\title{
Tratamentos pós-colheita e qualidade de hastes florais de Limonium sinuatum ${ }^{(1)}$
}

\author{
MARLISE NARA CIOTTA(2); EDUARDO DA COSTA NUNES(2)
}

\begin{abstract}
RESUMO
O gênero Limonium é composto de mais de 300 espécies, anuais e perenes. Uma delas é o Limonium sinuatum, que tem grande potencial para uso como flor de corte, tanto em arranjos florais frescos ou como flor seca. Para conservar a longevidade das hastes florais, normalmente são utilizadas soluções com sacarose. Os objetivos deste trabalho foram quantificar o tempo de desidratação de hastes florais de Limonium sinuatum e avaliar seu uso como flor desidratada e a durabilidade de hastes florais após a colheita, em diferentes concentrações de soluções com sacarose. Os resultados mostram que a desidratação total em estufa ocorreu em 36 horas, a $50^{\circ} \mathrm{C}$, e ao ar livre, após o $11^{\circ}$ dia de secagem. Em ambas as formas, as flores mantiveram as características, especialmente de coloração, enquanto as hastes escureceram. A longevidade das hastes florais é maior em soluções contendo sacarose e mantidas em condições de temperatura ambiente do que em câmara fria, a $9^{\circ} \mathrm{C}$. A durabilidade nestas condições foi igual ou superior a 8 ou 4 dias, respectivamente.

Palavras-chave: haste de corte, flor desidratada, conservação de hastes florais.
\end{abstract}

\section{Post-harvest treatments and quality flower Limonium sinuatum}

The genus Limonium is composed of more than 300 species, annuals and perennials. One is the Limonium sinuatum, which has great potential for use as cut flowers, floral arrangements in both, fresh or dried flower as well. To preserve the longevity of the flowers are usually used solutions with sucrose. Our objectives were to quantify the time of dehydration of flower stalks of Limonium sinuatum, and its use as a dried flower and assess the durability of flower stalks after harvest, in different concentrations of sucrose solutions. The results show that total greenhouse dehydration occurred at 36 hours and the open air after the 11th day of drying. In both forms, the flowers kept their characteristics, especially color, while the stems are dim. The longevity of the flowers was bigger in solutions containing sucrose stored under room temperature than in cold storage. The durability of these conditions was equal to or greater than 8 or 4 days, respectively. Keywords: stem cutting, dried flower, conservation floral stems.

\section{INTRODUÇÃO}

A floricultura é um dos setores da economia na área agrícola que vem se expandido de forma bastante significativa, abrangendo vários ramos, desde a produção de flores para corte, para vaso, para jardinagem e paisagismo e também para produção de flores frescas e/ou desidratadas para decoração, entre outros. $O$ faturamento do mercado de flores e plantas ornamentais cresceu $9 \%$ nos cinco primeiros meses de 2009, em comparação ao mesmo período de 2008 em Santa Catarina (ICEPA, 2009).

As flores cortadas representam as mais notáveis conquistas nacionais no âmbito do mercado interno da floricultura (JUNQUEIRA et al., 2008). Os últimos dados estatísticos do Instituto CEPA (2009) mostram que a participação das flores de corte no mercado nacional é de $40 \%$. Com relação a produtos para exportação, uma pesquisa de campo conduzida pelo IBRAFLOR (JUNQUEIRA et al., 2004) mostrou que as flores de corte representam 19,9\% da área total destinada à floricultura. Em 2007, o montante financeiro das exportações brasileiras representou uma participação percentual de 10,5\% nas flores frescas, 41,9\% nas mudas, $39,8 \%$ nos bulbos e $7,8 \%$ em produtos diversos (JUNQUEIRA e PEETZ, 2007).
Entre as flores de corte, podem-se destacar várias espécies de Limonium. este gênero pertencem mais de 300 espécies de plantas anuais e perenes de valor ornamental. A espécie L. sinuatum,conhecida pelo nome comum de statice, estátice, latifólia ou lavanda do mar, é uma planta anual, natural da região do Mediterrâneo, com bom desenvolvimento em regiões de clima ameno. É uma das mais populares flores de corte no mundo e continua a ser produzida em grandes quantidades. As inflorescências são duráveis, eretas, ramificadas e com numerosas flores, o que potencializa seu uso em arranjos florais. É utilizada especialmente como complemento floral para agregar cor, leveza e volume ao conjunto floral (STUMPF et al., 2005).

As flores são órgãos normalmente de natureza efêmera, que resultam em curta longevidade (CARNEIRO et al. 2002). Sendo assim, com o objetivo de promover a longevidade e qualidade das hastes florais, habitualmente é utilizada a água acrescida de substâncias como sacarose, ácido giberélico, entre outras. Quando se utiliza o açúcar em soluções conservantes, ele se acumula nas flores, aumentando a concentração osmótica, melhorando a capacidade de absorção, favorecendo a manutenção da turgidez das pétalas, contribuindo para o balanço hídrico dessas flores (DIAS-TAGLIACOZZO et al., 2005a,

\footnotetext{
(1) Recebido em 12/06/2010 e aceito para publicação em 08/08/2011.

(2) EPAGRI/ Estação Experimental de São Joaquim, E.E.S.J., Rua João Araujo Lima, 102. Bairro Jardim Caiçara. C.P. 81, 88.600-000 São Joaquim,

SC, fone (49) 3233-0324, e-mail: marlise@epagri.sc.gov.br; eduardon@epagri.sc.gov.br
} 
2005b). Além do uso de soluções conservantes, podem ser feitos cortes sucessivos na base da haste floral em que se deseja manter conservada a longevidade com qualidade. CARNEIRO et al. (2002) obtiveram resultados positivos com o corte periódico da base das hastes em zínia, o que resultou em melhoria na hidratação e longevidade das flores.

$\mathrm{Na}$ arte floral, existe uma demanda por produtos diversos, e neste segmento se inserem as flores secas ou desidratadas. Neste caso, além de características visíveis como comprimento da haste, tamanho e cor da flor, estão também outras como sensibilidade ao manuseio, qualidade após o proceso de desidratação, valor ornamental, enfim, atributos de grande importância para satisfação do consumidor e melhoria da aptidão de uso e do valor agregado à espécie.

Para uma região incipiente na produção de flores e plantas ornamentais, que ainda não tem uma logística eficiente de transporte rápido e comercialização, ou mesmo não possui um grande mercado consumidor próximo, mas que tenha condições climáticas diferenciadas que possibilitem a produção de flores normalmente não produzidas em outras regiões, caso da região serrana do Planalto Sul Catarinense, uma interessante alternativa de produção são as flores que apresentem durabilidade pós-colheita ou que possam ser utilizadas como flor desidratada.

Este trabalho foi conduzido com o objetivo de avaliar e estabelecer as formas mais adequadas de desidratação de hastes florais de Limonium sinuatum,em estufa e ao ar livre, mantendo a sua qualidade para uso como flor desidratada na composição de arranjos florais; avaliar a durabilidade e qualidade de hastes florais frescas após a colheita, em diferentes concentrações de soluções com sacarose, por determinados períodos.

\section{MATERIAIS E MÉTODOS}

O trabalho foi conduzido na Estação Experimental da Epagri de São Joaquim - SC. Para o experimento, foram utilizadas quatro variedades de Limonium sinuatum: 'Compindi White' - branca; 'Compindi Rose' - rosa; 'Compindi Blue' - azul; e 'Compindi Deep Blue' - azul escuro. Essas variedades foram semeadas em bandejas com substrato e mantidas em local protegido. Após a emergência, as mudas foram transplantadas ao final do mês de novembro, diretamente para o campo experimental, em canteiros com solo corrigido para $\mathrm{pH} 6,0$, na densidade de 12 plantas $/ \mathrm{m}^{2}$. As hastes florais foram coletadas no mês de janeiro.

Experimento 1 - Desidratação de hastes florais

Após a colheita, foram selecionadas hastes florais com mais de $45 \mathrm{~cm}$ de altura, divididas ao acaso e desidratadas em estufa a $50^{\circ} \mathrm{C}$ por $12,24,36,48$ e 60 horas; em temperatura ambiente (aproximadamente $25^{\circ} \mathrm{C}$ ), em galpão ventilado, onde foram mantidas por um período de 34 dias, na forma de ramalhetes pendurados. Foram utilizadas 4 hastes florais por repetição e 4 repetições por variedade. Foram avaliados o tempo para completa desidratação das hastes nos dois tratamentos e o aspecto geral das mesmas.
Experimento 2 - Conservação de hastes florais frescas

Para este experimento, foram selecionadas hastes florais com mais de $45 \mathrm{~cm}$ de comprimento, divididas ao acaso e submetidas aos tratamentos em temperatura ambiente (aproximadamente $25^{\circ} \mathrm{C}$ ) e em câmara fria $\left(9^{\circ} \mathrm{C}\right)$ : T1 - água destilada; T2 - água destilada com $10 \%$ de sacarose por um período de 2 horas; T3 - água destilada com $10 \%$ de sacarose por um período de 4 horas; T4 água destilada com $10 \%$ de sacarose por um período de 6 horas; T5 - água destilada com 10\% de sacarose por um período de 8 horas; T6 - água destilada com 5\% de sacarose por um período de 4 horas; T7 - água destilada com $15 \%$ de sacarose por um período de 4 horas; e T8 água destilada com $20 \%$ de sacarose por um período de 4 horas. Após os respectivos tratamentos, as hastes florais permaneceram em vasos somente com água destilada, renovada a cada $48 \mathrm{~h}$, por um período de 28 dias. A longevidade e a senescência das flores foram avaliadas a cada dois dias, com base na escala descritiva de qualidade, como segue: estádio I - boa turgidez e rigidez da haste floral e manutenção da coloração das flores; estádio II início de escurecimento da haste floral e de descoloração das flores; e estádio III - total escurecimento da haste floral e/ou descoloração das flores. O estádio III definiu o período máximo de longevidade da haste floral em termos de qualidade, a partir do qual considerou-se como havendo total perda do valor ornamental e comercial das mesmas. dados foram analisados utilizando-se a Análise de Variância em uma direção (ANOVA), com separação de médias pelo DMS ao nível de significância de 5\% $(\mathrm{P}<0.05)$.

\section{RESULTADOS E DISCUSSÃO}

\subsection{Conservação e qualidade de hastes florais de $L$. sinuatum após secagem em estufa a $50^{\circ} \mathrm{C}$ e ao ar livre}

A Figura 1 apresenta os dados de matéria seca de cada variedade, em função do tempo mantido em estufa.

Observa-se que o peso inicial em cada uma das quatro variedades foi diferente. A variedade de cor azul apresentou o maior peso inicial, $120 \mathrm{~g}$, comparado às variedades branca e rosa com 67 e $75 \mathrm{~g}$, respectivamente.

Após o período de 12 horas de secagem a $50^{\circ} \mathrm{C}$, o peso inicial foi reduzido em aproximadamente 50\%, com exceção da variedade azul, que se desidratou mais lentamente, possivelmente pelo fato de ter maior peso inicial, consequentemente, maior conteúdo de água.

No entanto, a partir de 36 horas em estufa, as quatro variedades estabilizaram o peso seco, quando se desidrataram totalmente.

Após 60 horas em estufa, as hastes mantiveram sua qualidade visual no que se refere à coloração de flores, embora as hastes tenham perdido sua coloração natural mais rapidamente. Limonium sinuatum é uma espécie ornamental muito apreciada como flor de corte para uso como complemento em arranjos ou como flor seca (STUMPF et al., 2005; LORENZI e SOUZA, 2001). Assim, não perde sua importância ornamental se somente a haste alterar a coloração verde natural. Em arranjos, neste caso, o destaque pode ser dado especialmente à flor. 

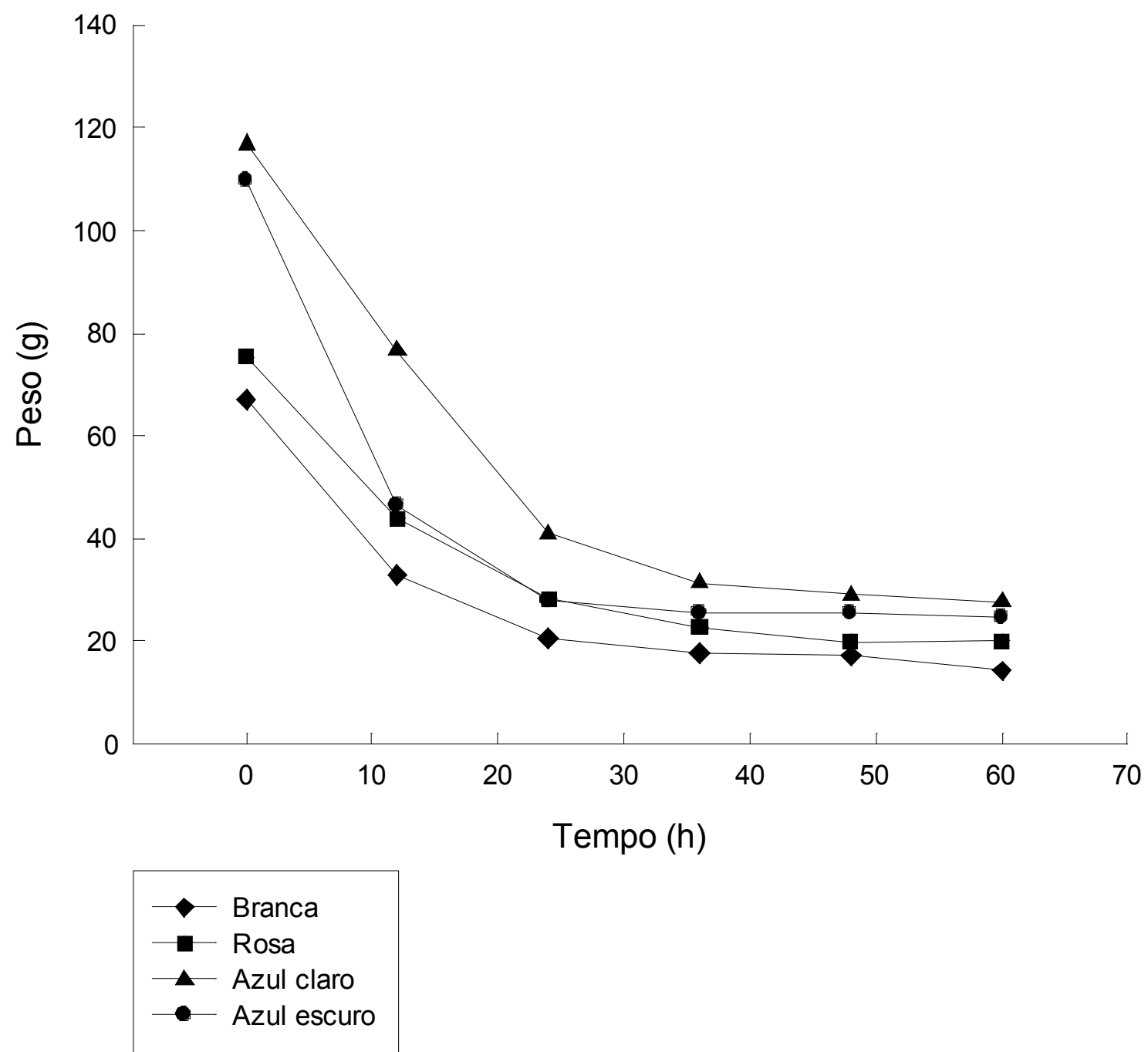

Figura 1. Peso seco de hastes florais de Limonium sinuatum em função do tempo de secagem em estufa a $50^{\circ} \mathrm{C}$.

Figure 1. Dry weight of flower stalks of Limonium sinuatum versus time of drying in an oven at $50^{\circ} \mathrm{C}$.

No método de secagem ao ar livre, independentemente do peso inicial das hastes florais, ocorreu estabilização a partir do $11^{\circ}$ dia de sua exposição à secagem (Figura 2). A partir do $5^{\circ}$ dia até o final da avaliação, não houve alteração do peso das hastes florais, demonstrando não haver reabsorção significativa de umidade pelo material. No entanto, cabe ressaltar que, neste tipo de desidratação, o período de exposição do material à secagem completa está muito relacionado às condições climáticas, podendo variar de acordo com a temperatura, o vento e, especialmente, com a umidade do ar.

Por outro lado, a técnica de secagem ao ar livre é a mais simples e natural. A vantagem deste método é a preservação da forma e da cor da maioria das espécies de flores e plantas. Embora existam diferenciações do método, como secagem das plantas em vaso ou deitadas, o uso de ramalhetes pendurados é o mais indicado para o Limonium, assim como para rosas, sempre-vivas, mil folhas e mimosas.

Da mesma forma que na desidratação a $50^{\circ} \mathrm{C}$, com temperatura controlada, as flores mantiveram sua coloração característica, demonstrando o bom potencial desta espécie para uso como flor desidratada.

\subsection{Conservação e qualidade de hastes florais de} Limonium sinuatum em solução de sacarose

A permanência das hastes no melhor estádio visual (I), para alguns tratamentos, foi até os 28 dias de avaliação, como pode ser visualizado na Tabela 1. Este é um dado muito importante, pois para a permanência de uma espécie no mercado, não só a qualidade estética e a facilidade de produção são suficientes, mas a durabilidade também é fator importante. Segundo BREDMOSE (1987), para garantir ao consumidor a manutenção da qualidade das flores por no mínimo sete dias, a durabilidade esperada deve ser de pelo menos duas semanas após a colheita. As flores de Limonium persistem aproximadamente duas semanas em água sem qualquer cuidado especial, embora as hastes possam secar antes com sintomas de Botrytis (ARMITAGE, 1993). 


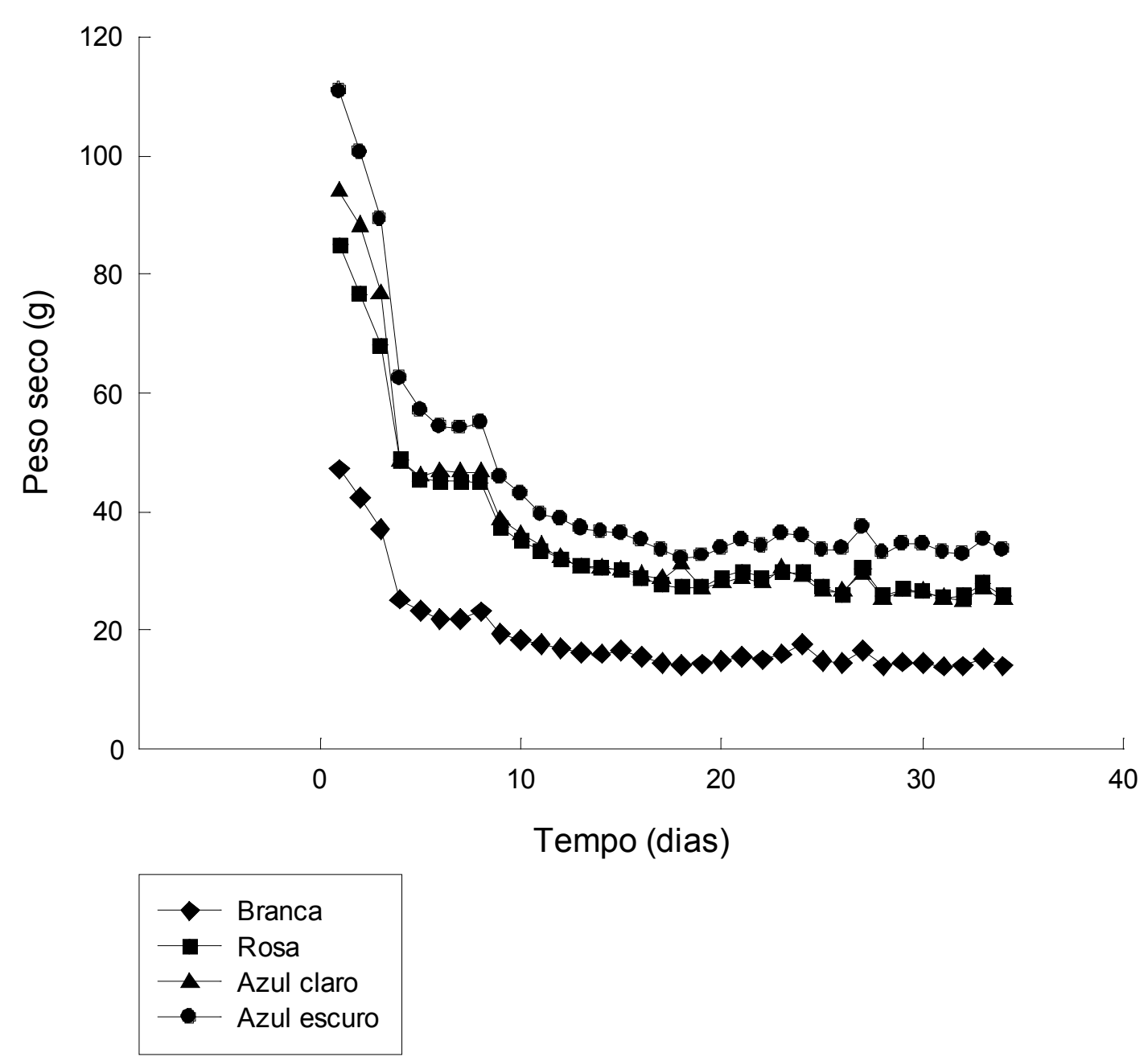

Figura 2. Peso seco de hastes florais de Limonium sinuatum em função do tempo de secagem em temperatura ambiente. Figure 2. Dry weight of flower stalks of Limonium sinuatum a function of drying time at room temperature.

De uma maneira geral, as quatro variedades estudadas apresentaram maior durabilidade quando mantidas em temperatura ambiente que em câmara fria.

Para a variedade branca, em temperatura ambiente, houve uma variação de 4 a 27 dias de durabilidade das hastes florais, sendo o melhor tratamento a solução de sacarose $(10 \%)$ por 6 horas, enquanto na câmara fria foi a solução com sacarose $15 \%$, por 4 horas, com durabilidade de hastes de 16 dias. A menor durabilidade ocorreu no tratamento sem sacarose independentemente da temperatura, e com sacarose (10\%) por 2,6 ou 8 horas, em câmara fria.

Para a variedade rosa houve uma variação entre 7 e 22 dias, e de 5 a 21 dias, respectivamente, para os tratamentos em temperatura ambiente e na câmara. Na temperatura ambiente, a maior durabilidade foi atingida com a solução de sacarose $(10 \%)$ por $2 \mathrm{~h}$, enquanto na câmara, três tratamentos se destacaram: sacarose $(10,15$ ou $20 \%)$ por duas horas. Comparando esta mesma variedade nas duas temperaturas, o melhor tratamento aconteceu com sacarose a $10 \%$ por duas horas, em temperatura ambiente, e a menor durabilidade em câmara fria, no mesmo tratamento.

As variedades de cor azul e azul escuro apresentaram durabilidade superior às anteriores, até 28 dias nos melhores tratamentos. A variedade azul durou 28 dias quando tratada com sacarose (20\%) por 4 horas, e apenas 10 dias quando submetida à solução de sacarose a $5 \%$ por 4 horas. Em câmara fria, destacou-se com a menor durabilidade, independentemente do tratamento, permanecendo maior número de dias em estádio intermediário (II), com hastes escurecidas. Já a variedade azul escura apresentou a maior durabilidade de hastes tanto em tratamento com sacarose a $20 \%$ por 4 horas, quanto na solução de sacarose a $10 \%$ por 6 horas; em solução com 10\% de sacarose por 8 horas, ela apresentou a pior performance, igualando-se ao tratamento somente com água (testemunha).

Existe uma grande variação de resultados entre as variedades. Porém, independentemente da temperatura avaliada, todas as variedades apresentaram maior durabilidade quando submetidas a soluções com sacarose. Segundo TAIZ e ZEIGER (2004), o efeito do açúcar pode estar associado à sua translocação e acúmulo nas flores, aumentando a concentração osmótica, melhorando a capacidade de absorção, favorecendo a manutenção da turgidez das pétalas e, consequentemente, o balanço hídrico das flores. 
Tabela 1. Durabilidade (dias) das hastes florais de Limonium sinuatum nos diferentes estádios de senescência, em diferentes temperaturas, para as variedades branca, rosa, azul claro e azul escuro, durante 28 dias de avaliação

Table 1. Durability (days) of the flowers of Limonium sinuatum at various stages of senescence at different temperatures, for the varieties white, pink, light blue and dark blue for 28 days evaluation

\begin{tabular}{|c|c|c|c|c|c|c|c|}
\hline \multirow{3}{*}{ Varied. } & \multirow{3}{*}{ Tratam } & \multicolumn{4}{|c|}{ Temp. ambiente } & & \multirow[b]{3}{*}{ III } \\
\hline & & \multirow[b]{2}{*}{ I } & \multicolumn{4}{|c|}{ Estádios de senescencia } & \\
\hline & & & II & III & I & II & \\
\hline \multirow{8}{*}{ Branca } & T 1 & $4 \mathrm{c}$ & $13 \mathrm{ab}$ & $11 \mathrm{a}$ & $6 \mathrm{~b}$ & $14 \mathrm{abc}$ & $9 \mathrm{abc}$ \\
\hline & T 2 & $18 \mathrm{ab}$ & $11 \mathrm{ab}$ & $0 \mathrm{~b}$ & $4 \mathrm{~b}$ & $9 \mathrm{c}$ & $16 \mathrm{a}$ \\
\hline & T 3 & $9 \mathrm{bc}$ & $20 \mathrm{a}$ & $0 \mathrm{~b}$ & $10 a b$ & $14 a b c$ & $5 \mathrm{bcd}$ \\
\hline & T 4 & $27 \mathrm{a}$ & $1 \mathrm{~b}$ & $0 \mathrm{~b}$ & $4 \mathrm{~b}$ & $20 \mathrm{a}$ & $4 \mathrm{bcd}$ \\
\hline & T 5 & $15 \mathrm{bc}$ & $13 \mathrm{ab}$ & $0 \mathrm{~b}$ & $4 \mathrm{~b}$ & $13 \mathrm{abc}$ & $11 \mathrm{ab}$ \\
\hline & T 6 & $16 \mathrm{ab}$ & $12 \mathrm{ab}$ & $0 \mathrm{~b}$ & $14 a b$ & $6 \mathrm{c}$ & $8 \mathrm{abc}$ \\
\hline & $\mathbf{T} 7$ & $10 \mathrm{bc}$ & $17 \mathrm{a}$ & $1 \mathrm{~b}$ & $16 \mathrm{a}$ & $10 \mathrm{bc}$ & $2 \mathrm{~cd}$ \\
\hline & T 8 & $10 \mathrm{bc}$ & $18 \mathrm{a}$ & $0 \mathrm{~b}$ & $11 \mathrm{ab}$ & $18 \mathrm{ab}$ & $0 \mathrm{~d}$ \\
\hline \multirow{8}{*}{ Rosa } & $\mathbf{T} 1$ & $12 \mathrm{c}$ & $16 \mathrm{ab}$ & $0 \mathrm{~b}$ & $16 a b$ & $12 \mathrm{a}$ & $0 \mathrm{~b}$ \\
\hline & $\mathbf{T} 2$ & $22 \mathrm{a}$ & $6 \mathrm{c}$ & $0 \mathrm{~b}$ & $6 \mathrm{~b}$ & $12 \mathrm{a}$ & $10 \mathrm{a}$ \\
\hline & T 3 & $20 \mathrm{ab}$ & $9 \mathrm{bc}$ & $0 \mathrm{~b}$ & $21 \mathrm{a}$ & $7 \mathrm{a}$ & $0 \mathrm{~b}$ \\
\hline & $\mathbf{T} 4$ & $8 \mathrm{c}$ & $15 \mathrm{ab}$ & $6 \mathrm{a}$ & $15 \mathrm{ab}$ & $13 \mathrm{a}$ & $0 \mathrm{~b}$ \\
\hline & $\mathbf{T} 5$ & $15 \mathrm{abc}$ & $13 \mathrm{abc}$ & $0 \mathrm{~b}$ & $14 \mathrm{ab}$ & $13 \mathrm{a}$ & $1 \mathrm{~b}$ \\
\hline & T 6 & $11 \mathrm{bc}$ & $17 \mathrm{a}$ & $0 \mathrm{~b}$ & $9 \mathrm{ab}$ & $10 \mathrm{a}$ & $9 \mathrm{a}$ \\
\hline & $\mathbf{T} 7$ & $14 \mathrm{abc}$ & $14 \mathrm{abc}$ & $0 \mathrm{~b}$ & $21 \mathrm{a}$ & $6 \mathrm{a}$ & $1 \mathrm{~b}$ \\
\hline & T 8 & $12 \mathrm{bc}$ & $16 a b$ & $0 \mathrm{~b}$ & $19 \mathrm{a}$ & $9 \mathrm{a}$ & $0 \mathrm{~b}$ \\
\hline \multirow{8}{*}{ Azul claro } & $\mathbf{T} 1$ & $12 \mathrm{bc}$ & $16 a b$ & $0 \mathrm{~b}$ & $8 \mathrm{a}$ & $18 \mathrm{a}$ & $3 \mathrm{a}$ \\
\hline & T 2 & $18 \mathrm{abc}$ & $10 \mathrm{abc}$ & $0 \mathrm{~b}$ & $10 \mathrm{a}$ & $12 \mathrm{ab}$ & $6 \mathrm{a}$ \\
\hline & T 3 & $20 \mathrm{ab}$ & 8 abc & $0 \mathrm{~b}$ & $14, \mathrm{a}$ & $10 \mathrm{ab}$ & $4 \mathrm{a}$ \\
\hline & $\mathbf{T} 4$ & $11 \mathrm{bc}$ & $12 a b$ & $5 \mathrm{a}$ & $6 \mathrm{a}$ & $18 \mathrm{a}$ & $4 \mathrm{a}$ \\
\hline & T 5 & $18 \mathrm{abc}$ & $11 \mathrm{ab}$ & $0 \mathrm{~b}$ & $9 \mathrm{a}$ & $13 \mathrm{ab}$ & $6 \mathrm{a}$ \\
\hline & T 6 & $10 \mathrm{c}$ & $18 \mathrm{a}$ & $0 \mathrm{~b}$ & $12 \mathrm{a}$ & $5 \mathrm{~b}$ & $12 \mathrm{a}$ \\
\hline & T 7 & $20 \mathrm{abc}$ & $8 \mathrm{bc}$ & $0 \mathrm{~b}$ & $5 \mathrm{a}$ & $16 \mathrm{ab}$ & $7 \mathrm{a}$ \\
\hline & T 8 & $28 \mathrm{a}$ & $0 \mathrm{c}$ & $0 \mathrm{~b}$ & $6 \mathrm{a}$ & $18 \mathrm{a}$ & $5 \mathrm{a}$ \\
\hline \multirow{8}{*}{$\begin{array}{c}\text { Azul } \\
\text { escuro }\end{array}$} & T 1 & $12 \mathrm{c}$ & $16 \mathrm{a}$ & $0 \mathrm{a}$ & $21 \mathrm{ab}$ & $4 \mathrm{ab}$ & $4 a b$ \\
\hline & T 2 & $27 \mathrm{ab}$ & $1 \mathrm{~b}$ & $0 \mathrm{a}$ & $13 \mathrm{~b}$ & $9 \mathrm{ab}$ & $7 \mathrm{a}$ \\
\hline & T 3 & $27 \mathrm{ab}$ & $1 \mathrm{~b}$ & $0 \mathrm{a}$ & $20 \mathrm{ab}$ & $6 a b$ & $3 a b$ \\
\hline & T 4 & $28 \mathrm{a}$ & $0 \mathrm{~b}$ & $0 \mathrm{a}$ & $20 \mathrm{ab}$ & $8 \mathrm{ab}$ & $0 \mathrm{~b}$ \\
\hline & T 5 & $11 \mathrm{c}$ & $16 \mathrm{a}$ & $2 \mathrm{a}$ & $27 \mathrm{a}$ & $1 \mathrm{~b}$ & $0 \mathrm{~b}$ \\
\hline & T 6 & $18 \mathrm{bc}$ & $8 a b$ & $2 \mathrm{a}$ & $19 a b$ & $5 \mathrm{ab}$ & $5 a b$ \\
\hline & T 7 & $22 \mathrm{ab}$ & $6 \mathrm{~b}$ & $0 \mathrm{a}$ & $16 \mathrm{~b}$ & $11 \mathrm{a}$ & $1 \mathrm{~b}$ \\
\hline & T 8 & $28 \mathrm{a}$ & $0 \mathrm{~b}$ & $0 \mathrm{a}$ & $28 \mathrm{a}$ & $0 \mathrm{~b}$ & $0 \mathrm{~b}$ \\
\hline
\end{tabular}




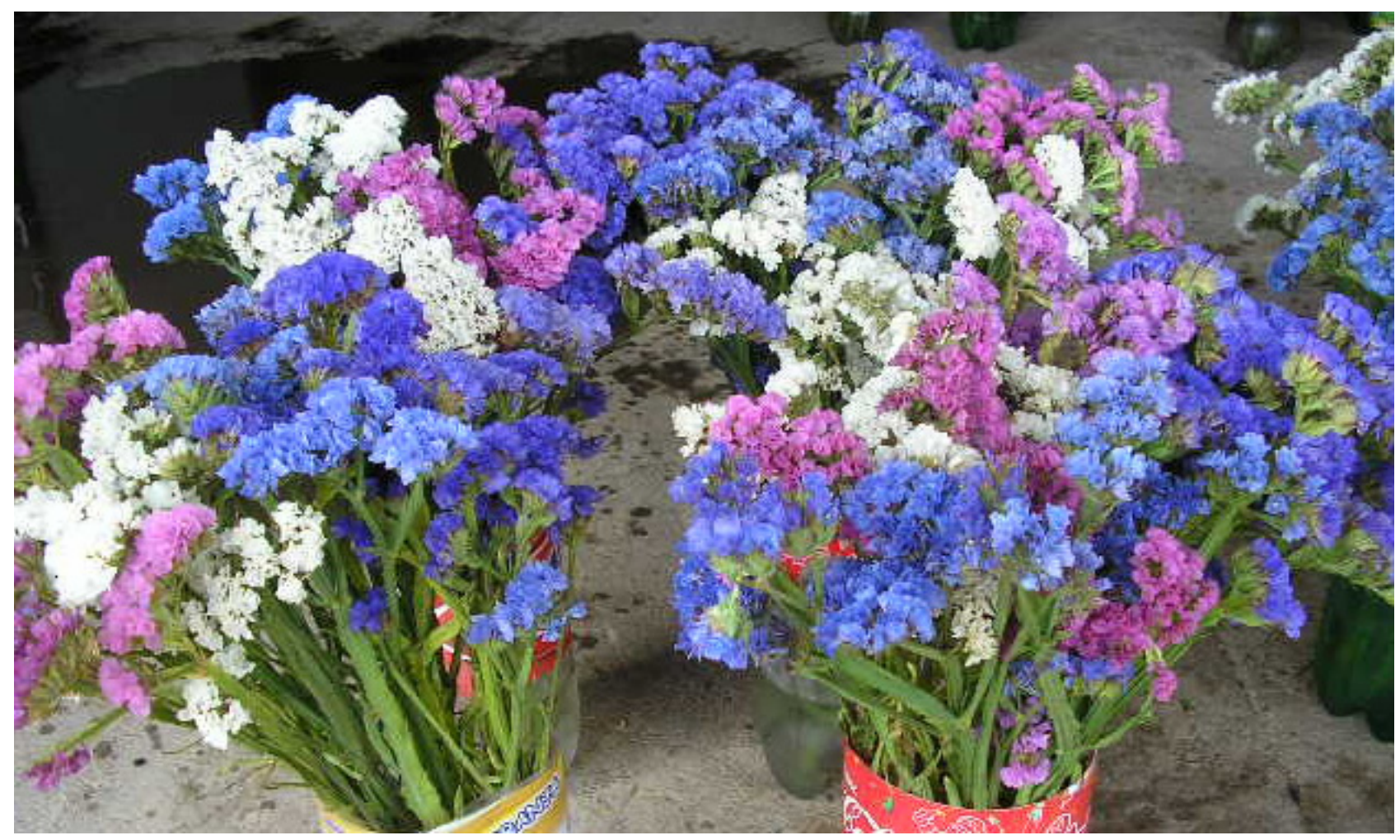

Figura 3. Hastes florais de Limonium sinuatum no início do período de conservação em solução com sacarose. Figure 3. Limonium sinuatum of flower stalks in early storage period with sucrose solution.

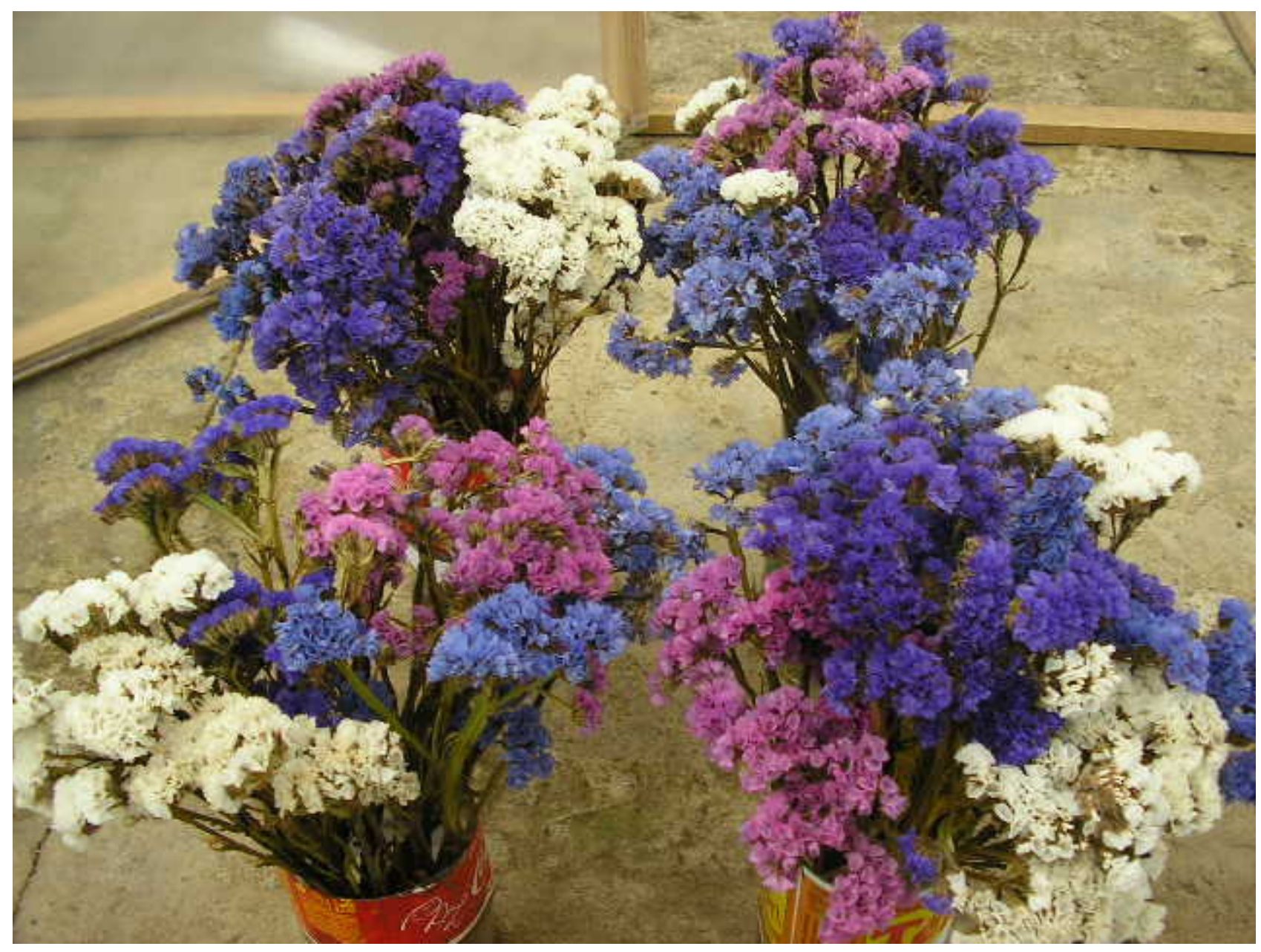

Figura 4. Hastes florais de Limonium sinuatum no período final de conservação em solução de sacarose.

Figure 4. Limonium sinuatum of flower stalks in final period of preservation with sucrose solution. 
Dados de DOI e REID (1995), para o caso de Limonium que abre os botões sequencialmente, o suprimento de açúcar foi essencial para continuar a abertura de botões após a colheita e, com isso, aumentar a longevidade das flores. Especialmente porque em flores de corte, com esta abertura sequencial de botões, há uma competição entre eles pelos carboidratos. Além disso, a sacarose também aumentou a longevidade das flores, talvez pela diminuição do potencial osmótico nas pétalas.

BURGE et al. (1998) observaram que as flores de Limonium 'Chorus Magenta' permaneceram abertas apenas por 5 dias quando submetidas a uma solução somente com água após a colheita; por outro lado, com a adição de 50 ou $100 \mathrm{~g} / \mathrm{L}$ de sacarose por 24 horas nas soluções dos tratamentos, este tempo de permanência de flores abertas foi ampliado para 16 dias. Resultados semelhantes foram citados por DIAS-TAGLIACOZZO et al. (2005b), em que o uso de uma solução de sacarose $4 \%$ associada a $200 \mathrm{mg} / \mathrm{L}$ de ácido cítrico prolongou a durabilidade comercial de hastes florais de lírio em dois dias em relação à solução somente com água.

Por outro lado, em experimentos com a espécie Zinnia elegans apresentados por CARNEIRO et al. (2002), a aplicação de sacarose não resultou na extensão da longevidade das flores.

Estes resultados sugerem que as respostas a soluções conservantes sejam muito dependentes da espécie e, inclusive, da variedade. A concentração ótima de açúcares e o período de exposição à solução variam com o tratamento a ser utilizado e com a espécie a ser conservada (DIASTAGLIACOZZO et al., 2002).

De uma maneira geral, no presente experimento, o escurecimento da haste foi o primeiro fator que demonstrou redução da qualidade das hastes para o comércio (Figuras 3 e 4). Ou seja, a coloração das flores, especialmente das variedades azul e azul escura, permaneceu por longo tempo. Estes dados demonstram o potencial da espécie para uso em arranjos florais pela alta durabilidade da flor. Em geral, hastes florais são consideradas de alta durabilidade quando permanecem por sete dias com aspecto geral bom. No caso deste estudo, os melhores tratamentos apresentaram períodos superiores.

\section{CONCLUSÕES}

As hastes florais de L. sinuatum, quando submetidas à secagem em estufa, atingiram peso constante a partir de 36 horas de secagem, independentemente da variedade e do seu peso inicial. Após serem desidratadas totalmente e mantidas em local seco, aerado e sob temperatura ambiente, as hastes mantêm sua qualidade comercial por período extremamente longo, além de 12 meses. As hastes mantidas em estufa por período maior que 60 horas mantiveram inalterada a coloração das flores, porém tiveram alterada consideravelmente a coloração verde da haste e se tornaram excessivamente quebradiças.

No método de secagem ao ar livre, independentemente do peso inicial das hastes florais, ocorreu a estabilização a partir do $11^{\circ}$ dia de sua exposição à secagem, permanecendo com excelente qualidade de coloração de flores e hastes por período bastante longo.
A utilização destas técnicas possibilita o uso das hastes em arranjos florais por um período longo, uma vez que as hastes desidratadas não perdem a qualidade desde que mantidas em ambientes arejados e secos.

Com relação à durabilidade em soluções aquosas, a maior longevidade de hastes ocorreu em soluções contendo sacarose, preferencialmente, quando mantidas em temperatura ambiente.

Houve grande variação de resultados entre as variedades em relação às diferentes concentrações de sacarose testadas. Independentemente da temperatura do ambiente de conservação, todas as variedades apresentaram maior durabilidade quando submetidas a soluções com sacarose, portanto, em arranjos com hastes frescas desta espécie, a solução conservante necessariamente deverá conter no mínimo $10 \%$ de sacarose. A longevidade mínima mantendo as flores com bom aspecto de coloração foi de 8 e 4 dias em temperatura ambiente e câmara fria, respectivamente.

\section{REFERÊNCIAS BIBLIOGRÁFICAS}

ARMITAGE, A. M. Specialty cut flowers: The production of annuals, perennials, bulbs and woody plantsfor fresh and dried cut flowers, Ed. 1, Portland, 1993, 636p.

BREDMOSE, N. Post harvest ability of some new cut flowers. Acta Horticulturae, Wageningen, v. 205, p. 187194. 1987.

BURGE, G. K.; et al. Postharvest characteristics of Limonium 'Chorus Magenta' inflorescences. New Zealand Journal of Crop and Horticultural Science, New Zealand, v. 26, p. 135-142, 1998.

CARNEIRO, T. F.; et al. Influência da sacarose e do corte da base da haste na longevidade de inflorescências de Zínia elegans. Pesquisa Agropecuária Brasileira, Brasília, v. 37, n. 8, 2002.

DIAS-TAGLIACOZZO, G. D; FINGER, F. L.; BARBOSA, J. G. Fisiologia pós-colheita de flores de corte. Revista Brasileira de Horticultura Ornamental, Campinas, v. 11, n. 2, p. 88-99, 2005a.

DIAS-TAGLIACOZZO, G. D.; GONÇALVES, C. CASTRO, C. E.F. de. Manutenção da qualidade póscolheita de lírio. Revista Brasileira de Horticultura Ornamental, Campinas, v. 11, n. 1, p. 29-34, 2005 b.

DIAS-TAGLIACOZZO, G. D.; GONÇALVES, C. CASTRO, C. E.F. de. Fisiologia pós-colheita de espécies ornamentais. In: WACHOWICZ, C.M. e CARVALHO, R. I. N. (org.) - Fisiologia Vegetal: produção e pós colheita, Curitiba: Champagnat, cap.13, p. 359-382, 2002.

DOI, M.; REID, M. S. Sucrose improves the postharvest life of cut flowers of a hybrid Limonium. HortScience, Alexandria, v. 30, p.1058-1060, 1995.

EMPRESA DE PESQUISA AGROPECUÁRIA E EXTENSÃO RURAL DE SANTA CATARINA - EPAGRI; 
CENTRO DE SOCIOECONOMIA E PLANEJAMENTO AGRÍCOLA - EPAGRI/CEPA. Síntese Anual da Agricultura de Santa Catarina 2008-2009. Disponível em: < http://cepa.epagri.sc.gov.br/Publicacoes/sintese 2009/sintese_2009.pdf $>$ Acesso em 01 de fevereiro de 2010 .

JUNQUEIRA, A. H.; PEETZ, M. da S. Pesquisa qualitativa sobre o potencial exportador de flores e plantas ornamentais do Brasil. Campinas: Ibraflor / APEX-Brasil: Programa FloraBrasilis, 2004, 1, CD-ROM.

JUNQUEIRA, A. H.; PEETZ, M. da S. Mercado interno para os produtos da floricultura brasileira: características, tendências eimportância socioeconômica recente. Revista Brasileira de Horticultura Ornamental, Campinas, v. 14, n. 1, p. 37-52, 2008.

JUNQUEIRA, A. H.; PEETZ, M. da S. Exportações de flores e plantas ornamentais superam US\$ 35 milhões em 2007: recordes e novos desafios para o Brasil. Hórtica Consultoria e Treinamento, 2007. Disponível em: $<$ http:// www.hortica.com.br/artigos/Balanc_Floricultura_2007. pdf $>$. Acesso em 15 de abril de 2011.

LORENZI, H. S.; HERMES, M. Plantas ornamentais no Brasil: arbustivas, herbáceas e trepadeiras. $3^{\mathrm{a}}$ ed. Nova Odessa, 2001, p. 896.

SEBRAE. Expansão da Floricultura. Sebrae agronegócios. Brasília, n.1, p.16-18, 2005.

STUMPF, E. R. T., FISCHER, S. Z., BARBIERI, R. L. GARRASTAZU, $O$ setor produtivo de plantas ornamentais nos Coredes Sul e Centro Sul do Rio Grande do Sul. Pelotas: Embrapa Clima Temperado, 2005. 26p. (Embrapa, Documentos versão on line, 175).

TAIZ, L., ZEIGER, E. Fisiologia Vegetal. $3^{\mathrm{a}}$ ed. Porto Alegre, Artmed, 2004. p. 61-91. 